\title{
Desempenho e digestibilidade dos nutrientes de rações com casca do grão de soja em substituição ao milho para cabras Saanen em lactação e no pré-parto ${ }^{1}$
}

\author{
Maximiliane Alavarse Zambom ${ }^{2 *}$, Claudete Regina Alcalde ${ }^{3}$, Karina Toledo da Silva ${ }^{2}$, \\ Francisco de Assis Fonseca de Macedo $^{3}$, Carlos Eduardo Crispim Oliveira Ramos ${ }^{4}$, Gabriella \\ de Oliveira Passianoto ${ }^{5}$
}

\author{
1 Projeto financiado pela Fundação Araucária - Paraná \\ 2 Programa de Pós-graduação em Zootecnia, UEM. \\ ${ }^{3}$ Departamento de Zootecnia - UEM. Av. Colombo 5790, CEP: 87020-900, Maringá - PR. Pesquisador CNPq \\ ${ }^{4}$ Curso de Graduação em Zootecnia. Bolsista PIBIC/CNPq. \\ ${ }^{5}$ Curso de Graduação em Zootecnia. Bolsista IC/CNPq.
}

RESUMO - Objetivou-se com este experimento avaliar o desempenho produtivo, a digestibilidade da matéria seca e dos nutrientes e a composição do leite de cabras Saanen alimentadas com rações contendo casca do grão de soja (CGS) em substituição ao milho $(0,50$ ou $100 \% \mathrm{CGS})$ no período da lactação até o pré-parto (30 dias). Foram utilizadas 18 cabras $(75,70 \pm 10,59 \mathrm{~kg})$ em delineamento inteiramente casualizado. As dietas apresentaram em média 14,82\% PB e 2,28 Mcal de EM/kg MS ingerida Os animais foram mantidos confinados em baias individuais com controle diário da ração ingerida e da produção de leite. No 150 o dia de lactação, e também no 20 o dia anterior à data prevista para o parto, iniciou-se a coleta de fezes para determinação da digestibilidade da ração e dos nutrientes. Mensalmente, foram coletadas amostras de leite para análise dos principais constituintes. Os níveis de CGS não influenciaram o peso corporal (PC), as ingestões de matéria seca (IMS) e matéria orgânica (IMO), a digestibilidade de matéria seca (DMS), matéria orgânica (DMO) e proteína bruta (DPB) para produção de leite, a eficiência de produção de leite e a composição do leite no período de lactação. Também não afetaram o PC e as digestibilidades de MS e MO no período pré-parto. Os níveis de CGC influenciaram as ingestões de proteína bruta e fibra em detergente neutro e a digestibilidade da fibra em detergente neutro nos dois períodos avaliados. No período pré-parto, os maiores resultados para ingestão de MS e MO, digestibilidade da PB e nitrogênio uréico no plasma foram obtidos no nível de 100\%CGS. A utilização de casca do grão de soja em substituição ao milho moído na alimentação de cabras Saanen em lactação não altera o desempenho produtivo e a composição do leite.

Palavras-chave: caprinos, digestão, leite, subproduto da agroindústria

\section{Performance and nutrients digestibility of rations with soybean hulls as a corn ground replacement for Saanen goats, in prepartum and lactation}

ABSTRACT - This experiment was carried out to evaluate productive performance, dry matter and nutrient digestibility, and milk composition of Saanen goats fed rations with soybean hulls (SBH) as a corn ground replacement $(0$, 50 and $100 \% \mathrm{SBH})$, during lactation until prepartum (30 days). Eighteen goats were used $(75.70 \pm 10.59 \mathrm{~kg})$ in a completely randomized design. The rations presented $14.82 \% \mathrm{CP}$ and $2.28 \mathrm{Mcal} \mathrm{ME} / \mathrm{kg} \mathrm{DM}$ intake. The animals were confined in individual pens, with daily control of ration intake and milk production. At the $150^{\text {th }}$ lactation day and also 20 th days before kidding, fecal sampling started to be collected to determine ration and nutrient digestibilities. Monthly, milk samples were collected to analyses the main constituents. The levels of SBH did not affect body weight (BW), dry matter (DMI) and organic matter (OMI) intake, dry matter (DMD), organic matter (OMD) and crude protein (CPD) digestibility for milk production, milk production efficiency and milk composition during lactation; likewise for BW and digestibilities of DM and OM in prepartum period. The SBH influenced the intakes of crude protein, neutral detergent fiber and digestibility of neutral detergent fiber in the two evaluated periods. In prepartum period, the greatest results for DM and OM intakes, digestibility of CP and plasma urea nitrogen were obtained with the level of $100 \% \mathrm{SBH}$. Soybean hulls can be used as a corn ground replacement in rations for lactating Saanen goats without changes in productive performance and milk composition.

Key Words: by-product feed, digestion, goat, milk

Este artigo foi recebido em 10/11/2006 e aprovado em 3/1/2008. 


\section{Introdução}

A produção e a composição do leite de cabra estão diretamente relacionadas ao tipo e à composição da dieta dos animais, à raça, ao período de lactação e clima, além da ação combinada destes fatores nas condições ambientais de cada país ou região. O manejo alimentar é determinante na produção e composição do leite caprino, que dependem da quantidade e composição da dieta ofertada (Queiroga \& Costa, 2004).

Estudos têm demonstrado a importância da energia da dieta no desempenho de cabras em lactação (Schmidely et al., 1999; Zambom et al., 2005). Entretanto, a maioria dos alimentos concentrados utilizados baseia-se em grãos de cereais contendo amido rapidamente degradáveis, principal fonte de carboidrato. A fermentação do amido e dos açúcares solúveis pode gerar lactato como produto final da degradação ruminal, o que contribui para a redução no $\mathrm{pH}$ e digestão da fibra no rúmen. Além disso, estes carboidratos tendem a produzir menor razão acetato:propionato, resultando em menor teor de gordura no leite.

No entanto, a casca do grão de soja (CGS), um resíduo da agroindústria classificado pelo NRC (1996) como um alimento volumoso seco, apresenta $66,30 \%$ de fibra em detergente neutro e pode substituir alimentos concentrados energéticos e/ou parcialmente volumosos nas rações de ruminantes. Zambom et al. (2001) e Silva et al. (2004), realizando ensaios de digestibilidade in vitro da parede celular, pelo método de rúmen artificial ANKOM $^{\circledR}$, observaram valores de $95,69 \%$ e $85,65 \%$, respectivamente, demonstrando elevada digestibilidade da casca do grão de soja.

Ipharraguerre \& Clark (2003), em revisão sobre o valor nutritivo e os efeitos da casca do grão de soja na fermentação ruminal, concluíram que a CGS pode substituir o milho triturado em até $30 \%$ da MS da ração, sem afetar negativamente a fermentação ruminal, a ingestão e digestão dos nutrientes e o desempenho de vacas em lactação.

O aumento da ingestão durante o período de transição (21 dias pré-parto até 21 dias pós-parto) é fundamental para aumentar o suprimento de energia, de proteína e de ácidos graxos voláteis no rúmen, o que evita a mobilização de tecidos corporais e diminui a ocorrência de doenças metabólicas (Rodrigues, 2004). A baixa ingestão no período préparto decorre da limitada capacidade de ingestão, pois é no terço final da gestação que ocorre o maior crescimento do feto, o que leva a redução no volume do rúmen, em virtude da compressão do útero, podendo acarretar reduções de 25 a 35\% do consumo em vacas leiteiras (Drackley, 1999). No entanto, esta redução pode chegar a valores superiores para cabras do pré-parto ao início de lactação.

A ingestão de ração com nível energético semelhante (45 a 50\% de concentrado) promoveu diferenças na produção e composição do leite de vacas (DePeters et al., 1992). Schmidely et al. (1999). No entanto, Schimidely et al. (1999), trabalhando com cabras em lactação alimentadas com alta concentração de amido ou alto teor de fibra na dieta, não verificaram diferenças no peso corporal (PC), no consumo e na produção de leite.

Coomer et al. (1993) e Ipharraguerre et al. (2002a) avaliaram a utilização de CGS na dieta de vacas em lactação, e não verificaram diferenças na produção de leite, nas porcentagens de proteína e de lactose no leite e para concentração de uréia no leite. Entretanto, notaram efeito linear positivo na porcentagem de gordura no leite.

O objetivo neste trabalho foi avaliar a ingestão e a digestibilidade da matéria seca e dos nutrientes e a produção e composição do leite de cabras Saanen recebendo rações com casca do grão de soja em substituição ao milho no período da lactação até o pré-parto.

\section{Material e Métodos}

Oexperimento foi conduzido no Setor de Caprinocultura da Fazenda Experimental de Iguatemi e no Laboratório de Análise de Alimentos e Nutrição Animal da Universidade Estadual de Maringá no período de outubro de 2003 a julho de 2004.

Foram utilizadas 18 cabras Saanen $(75,70 \pm 10,59 \mathrm{~kg})$, avaliadas do $60^{\circ}$ dia de lactação até a próxima parição, perfazendo aproximadamente 275 dias de experimento, subdivididos em dois períodos: lactação ( $185 \pm 23,8$ dias $) \mathrm{e}$ pré-parto (30 dias finais de gestação). Os critérios para alocação dos animais nos tratamentos foram: nível de produção de leite (de lactações anteriores e dos 60 dias iniciais de lactação), PC, idade e ordem de parto. As cabras foram mantidas em baias individuais contendo bebedouro e comedouro. $\mathrm{O}$ fornecimento das rações foi realizado duas vezes ao dia, às $10 \mathrm{~h}$ e $16 \mathrm{~h}$. Foram realizadas duas ordenhas ao dia (7h30 e 15 h) e, logo após a ordenha da manhã, os animais foram conduzidos a um solário, onde permaneceram por aproximadamente 2 horas.

Foram utilizadas rações (Tabelas 1, 2 e 3 ) com 0,50 ou $100 \%$ de casca do grão de soja (CGS) em substituição ao milho. O balanceamento das rações foi feito com base nas exigências de energia e proteína metabolizável do AFRC (1993) e nas exigências em minerais do NRC (1981), considerando uma cabra Saanen de $60 \mathrm{~kg}$ PC e produção de $3,0 \mathrm{~kg}$ de leite por dia. 
Tabela 1 - Composição química dos alimentos (\% MS)

\begin{tabular}{lcccc}
\hline Nutriente & \multicolumn{4}{c}{ Alimento } \\
\cline { 2 - 5 } & $\begin{array}{c}\text { Milho } \\
\text { moído }\end{array}$ & $\begin{array}{c}\text { Farelo } \\
\text { soja }\end{array}$ & $\begin{array}{c}\text { Casca } \\
\text { grão soja }\end{array}$ & $\begin{array}{c}\text { Silagem } \\
\text { milho }\end{array}$ \\
\hline Período de lactação & & & \\
\hline Matéria seca (\%) & 88,85 & 90,50 & 92,60 & 29,07 \\
Matéria orgânica (\%MS) & 98,93 & 93,33 & 92,78 & 96,00 \\
Proteína bruta (\%MS) & 8,38 & 49,56 & 15,45 & 6,36 \\
Extrato etéreo (\%MS) & 3,59 & 2,10 & 2,43 & 2,42 \\
FDN (\%MS) & 12,34 & 14,85 & 60,74 & 60,38 \\
FDA (\%MS) & 3,81 & 10,32 & 46,81 & 30,04 \\
FDNI (\%MS) & 2,36 & 1,70 & 9,60 & 28,76 \\
EM (Mcal/kg de MS) & 3,21 & 3,01 & 2,10 & 2,27 \\
\hline Período pré-parto & \multicolumn{4}{c}{} \\
\hline Matéria seca (\%) & 88,40 & 88,69 & 90,89 & 29,08 \\
Matéria orgânica (\%MS) & 98,53 & 93,43 & 91,62 & 95,27 \\
Proteína bruta (\%MS) & 8,85 & 50,05 & 17,65 & 5,76 \\
Extrato etéreo (\%MS) & 4,51 & 2,28 & 3,22 & 1,67 \\
FDN (\%MS) & 16,28 & 14,15 & 53,13 & 65,19 \\
FDA (\%MS) & 4,50 & 9,09 & 39,75 & 38,95 \\
FDNI (\%MS) & 2,43 & 1,65 & 11,56 & 38,46 \\
EM (Mcal/kg de MS) ${ }^{1}$ & 3,11 & 3,02 & 2,12 & 2,13 \\
\hline
\end{tabular}

${ }^{1}$ Estimada por meio de fórmulas do NRC (2001); EM = 1,01*ED - 0,45.

Tabela 2 - Composição das rações fornecidas no período de lactação (\%MS)

\begin{tabular}{|c|c|c|c|}
\hline \multirow[t]{2}{*}{ Item } & \multicolumn{3}{|c|}{ Nível de casca do grão de soja (\%) } \\
\hline & 0 & 50 & 100 \\
\hline \multicolumn{4}{|l|}{ Ingrediente } \\
\hline Silagem de milho & 40,00 & 40,00 & 40,00 \\
\hline Farelo de soja & 17,29 & 18,27 & 16,78 \\
\hline Milho moído & 40,19 & 20,18 & - \\
\hline Casca do grão de soja & - & 19,46 & 41,32 \\
\hline Sal comum & 1,21 & 1,21 & 1,22 \\
\hline Calcário calcítico & 0,63 & 0,25 & - \\
\hline Fosfato bicálcico & 0,19 & 0,14 & 0,16 \\
\hline Suplemento mineral ${ }^{1}$ & 0,50 & 0,50 & 0,50 \\
\hline \multicolumn{4}{|l|}{ Composição analisada } \\
\hline Matéria seca $(\%)$ & 65,52 & 66,21 & 66,96 \\
\hline Matéria orgânica (\%MS) & 94,45 & 93,70 & 92,74 \\
\hline Proteína bruta (\%MS) & 13,29 & 15,03 & 15,98 \\
\hline Extrato etéreo (\%MS) & 2,58 & 2,40 & 2,22 \\
\hline Amido (\%MS) & 35,81 & 22,85 & 9,75 \\
\hline FDN (\%MS) & 30,88 & 39,76 & 49,65 \\
\hline FDA (\%MS) & 14,99 & 22,84 & 31,49 \\
\hline $\mathrm{CT}(\% \mathrm{MS})^{2}$ & 72,46 & 70,86 & 69,87 \\
\hline $\mathrm{Ca}(\% \mathrm{MS})$ & 0,41 & 0,36 & 0,38 \\
\hline $\mathrm{P}(\% \mathrm{MS})$ & 0,26 & 0,25 & 0,23 \\
\hline EM $(\mathrm{Mcal} / \mathrm{kg} \text { de } \mathrm{MS})^{3}$ & 2,49 & 2,33 & 2,14 \\
\hline \multicolumn{4}{|c|}{$\begin{array}{l}1 \text { Composição química (por kg do produto): Ca }-80,00 \mathrm{~g} ; \mathrm{P}-65,00 \mathrm{~g} \text {; } \\
\text { Co }-126,00 \mathrm{mg} ; \mathrm{Mg}-21,00 \mathrm{mg} ; \mathrm{Mn}-4.400,00 ; \mathrm{Na}-185,00 \mathrm{mg} ; \\
\mathrm{Zn}-4.680,00 \mathrm{mg} ; \mathrm{Se}-45,00 \mathrm{mg} ; \mathrm{I}-60,00 \mathrm{mg} ; \mathrm{S}-23,00 \mathrm{~g} ; \mathrm{F} \text { (máximo) } \\
-615,79 \mathrm{mg} ; \text { niacina (produto comercial) }-7000,00 \mathrm{mg} \text {. } \\
{ }^{2} \text { Estimado utilizando-se a fórmula de Sniffen et al. (1992): CT = } 100-(\% \mathrm{~PB} \\
\text { +\%EE + \%Cinzas). }\end{array}$} \\
\hline
\end{tabular}

Tabela 3 - Composição das rações fornecidas no período préparto (\%MS)

\begin{tabular}{|c|c|c|c|}
\hline \multirow[t]{2}{*}{ Item } & \multicolumn{3}{|c|}{ Nível de casca do grão de soja (\%) } \\
\hline & 0 & 50 & 100 \\
\hline
\end{tabular}

Ingrediente

\begin{tabular}{lccc}
\hline Silagem de milho & 40,00 & 40,00 & 40,00 \\
Farelo de soja & 17,29 & 18,27 & 16,78 \\
Milho moído & 40,19 & 20,18 & - \\
Casca do grão de soja & - & 19,46 & 41,32 \\
Sal comum & 1,21 & 1,21 & 1,22 \\
Calcário calcítico & 0,63 & 0,25 & - \\
Fosfato bicálcico $_{\text {Suplemento mineral }}{ }^{2}$ & 0,19 & 0,14 & 0,16 \\
\hline Composição analisada $^{2}$ & & & \\
\hline Matéria seca (\%) & 65,03 & 65,46 & 65,95 \\
Matéria orgânica (\%MS) & 94,05 & 93,20 & 92,10 \\
Proteína bruta (\%MS) & 13,13 & 15,11 & 16,38 \\
Extrato etéreo (\%MS) & 2,62 & 2,41 & 2,22 \\
Amido (\%MS) & 35,65 & 22,92 & 10,06 \\
FDN (\%MS) & 34,03 & 40,67 & 48,13 \\
FDA (\%MS) & 18,57 & 24,88 & 31,86 \\
CT (\%MS) & 71,70 & 69,50 & 67,82 \\
Ca (\%MS) & 0,41 & 0,36 & 0,37 \\
P (\%MS) & 0,26 & 0,24 & 0,23 \\
EM (Mcal/kg de MS) ${ }^{3}$ & 2,38 & 2,24 & 2,07 \\
\hline
\end{tabular}

${ }^{1}$ Composição química (por kg do produto): Ca - 80,00 mg; P - 65,00 g; Co - 126,00 mg: Mg - 21,00 g: Mn - 4.400,00 mg: Na - 185,00 mg; Zn - 4.680,00 mg; Se - 45,00 mg; I - 60,00 mg; S - 23,00 g; F (max.) - 615,79 mg; niacina (produto comercial) $-7.000,00 \mathrm{mg}$.

2 Estimado utilizando-se a fórmula de Sniffen et al. (1992): CT = $100-(\%$ PB $+\% \mathrm{EE}+\%$ Cinzas)

${ }^{3}$ Estimada utilizando-se a fórmula do NRC (2001): EM = 1,01*ED - 0,45.

A pesagem das rações fornecidas (silagem de milho e concentrado) e das sobras foi realizada diariamente. Quinzenalmente foram realizadas amostragens das rações fornecidas e das sobras para composição de duas amostras compostas, uma do período de lactação e outra do período pré-parto. As amostras foram moídas utilizando-se peneira com crivos de $1 \mathrm{~mm}$ e acondicionadas em frascos para posteriores análises.

No início do experimento e a cada 15 dias, foram realizadas as pesagens dos animais, logo após a ordenha e antes da alimentação da manhã. Durante o período de lactação avaliado, realizou-se o controle diário da produção de leite. Para a análise da composição físico-química do leite, foram coletadas amostras (7h30 e $15 \mathrm{~h}$ ) mensalmente.

A densidade do leite foi determinada em termolactodensímetro de Quevene. Os valores obtidos foram corrigidos para $15^{\circ} \mathrm{C}$, por meio da tabela de Tronco (1997). A acidez do leite foi verificada utilizando-se o método de titulação Dornic (Tronco, 1997).

As análises do leite foram feitas em amostras acondicionadas em frasco plástico contendo conservante 
Bronopol (2-bromo-2-nitro-1,3-propanodiol). As amostras foram enviadas ao laboratório do Programa de Análises do Rebanho Leiteiro do Paraná (PARLPR), da Associação Paranaense de Criadores de Bovinos da Raça Holandesa, onde foram analisadas quanto aos teores de gordura, proteína, lactose e sólidos totais, pelo analisador infravermelho Bentley $2000^{\circledR}$. A contagem de células somáticas foi realizada utilizando-se o contador eletrônico Somacount $500^{\circledR}$. Os equipamentos foram calibrados para análise de leite de vaca.

A produção de leite foi corrigida para 3,5\% de gordura, segundo a equação de Gravert (1987):

$$
\operatorname{LCG}(3,5 \%)=0,4337 \mathrm{PL}+16,218 \mathrm{PG}
$$

em que: LCG: leite corrigido para gordura; PL: produção de leite (kg/dia); PG: produção de gordura (kg/dia).

A determinação da concentração de nitrogênio uréico no leite foi feita utilizando-se amostras referentes ao $90^{\circ}$ dia de experimento, isto é, aproximadamente no $150^{\circ}$ dia de lactação, as quais foram congeladas e armazenadas. A gordura do leite foi extraída por procedimento em centrífuga refrigerada a $8^{\circ} \mathrm{C}$, por 30 minutos, a uma rotação de $3.000 \mathrm{rpm}$, sendo que o soro obtido após centrifugação foi utilizado para determinação da concentração de nitrogênio uréico no leite, pelo método colorimétrico (Marsh et al., 1965).

No período pré-parto, foram realizadas coletas de sangue 4 horas após a alimentação da manhã, por meio de punção da veia jugular. A obtenção do plasma foi feita por centrifugação a $3.500 \mathrm{rpm}$ por 15 minutos. O plasma foi identificado e congelado para análise da concentração de nitrogênio uréico pelo mesmo método utilizado na análise no leite.

Para determinação da digestibilidade da matéria seca e dos nutrientes, no $150^{\circ}$ - dia de lactação e no $20^{\circ}$ dia anterior ao parto, foram realizadas coletas de fezes diretamente no reto, durante seis dias, às $8,10,12,14,16$ e $18 \mathrm{~h}$, respectivamente, a cada dia. Para obtenção das estimativas de excreção fecal, utilizou-se como indicador a FDN indigestível (FDNi), conforme proposto por Cochran et al. (1986). A FDNi foi estimada pela incubação no rúmen de filtros F57 da ANKOM $^{\circledR}$, por 144 horas, de amostras de alimento, sobras e fezes, seguida da análise de fibra em detergente neutro.

As amostras de ração fornecida, sobras e fezes foram analisadas quanto aos teores de matéria seca, cinzas, proteína bruta, cálcio e fósforo segundo metodologias descritas por Silva \& Queiroz (2004), e de fibra em detergente neutro e em detergente ácido, segundo metodologia de Van Soest et al. (1991). Os carboidratos totais (CT) e os nutrientes digestíveis totais (NDT) foram estimados segundo equações descritas por Sniffen et al. (1992). Para a determinação do amido, utilizou-se o método enzimático adaptado por Pereira \& Rossi (1995).

Utilizou-se o delineamento inteiramente casualizado, com seis repetições por tratamento. Os dados foram analisados por meio de análise de variância utilizando-se o teste Tukey a $5 \%$ de probabilidade, pelo programa SAEG (Sistema para Análises Estatísticas e Genéticas), desenvolvido pela Universidade Federal de Viçosa (UFV, 1997). O modelo estatístico foi:

$$
Y i j=\mu+T i+e i j
$$

em que: $Y i j=$ observação do animal j recebendo o tratamento i, $\mathrm{i}=0,50$ e $100 ; \mu=$ constante geral; $\mathrm{Ti}=$ efeito do tratamento i, i= 0, 50 e 100; eij = erro aleatório associado a cada observação.

\section{Resultados e Discussão}

Não foram observadas diferenças $(\mathrm{P}>0,05)$ entre os tratamentos para peso corporal final e ingestões de matéria seca (IMS) e matéria orgânica (IMO), entretanto, para ingestão de proteína bruta (IPB) e de fibra em detergente neutro (IFDN), foram observados maiores valores para o tratamento $100 \%$ CGS (Tabela 4), provavelmente em virtude da composição das rações, pois a inclusão da CGS elevou os teores de PB e de FDN.

A diferença no teor de proteína bruta das rações quando incluída CGS foi ocasionada pela presença de grãos de soja no lote de CGS utilizado, pois o teor de PB da CGS foi superior $(15,45 \%)$ aos valores observados na literatura, de $12 \%$ de PB (NRC, 1996).

Ipharraguerre et al. (2002a) e Ipharraguerre et al. (2002b) trabalhando com vacas da raça Holandesa em meio de lactação, Zambom et al. (2007) trabalhando com cabras Saanen $(52,35 \mathrm{~kg} \pm 7,46)$ em lactação, e Hashimoto et al. (2007), utilizando cabritos em crescimento, avaliaram a substituição do milho moído por CGS e não verificaram diferenças para IMS e IPB, no entanto, observaram efeito linear positivo da inclusão de CGS na ração sobre a IFDN. Assim, o aumento da ingestão da fibra provinda da CGS não interfere na ingestão de matéria seca.

Para digestibilidade da matéria seca (DMS), da matéria orgânica (DMO) e da proteína bruta (DPB), não foi detectado efeito $(\mathrm{P}>0,05)$ da inclusão da CGS. Contudo, houve diferença $(\mathrm{P}<0,05)$ para digestibilidade da fibra em detergente neutro (DFDN), que foi maior com a substituição total do milho por casca do grão de soja, confirmando que a FDN da CGS é de alta digestibilidade, 95,69\% (Zambom et al., 2001). 
Tabela 4 - Peso vivo inicial (PVI) e final (PVF) e ingestão e digestibilidade de nutrientes em cabras Saanen em lactação alimentadas com rações contendo casca do grão de soja em substituição ao milho moído

\begin{tabular}{|c|c|c|c|c|c|}
\hline \multirow[t]{2}{*}{ Item } & \multicolumn{3}{|c|}{$\begin{array}{l}\text { Nível de casca do } \\
\text { grão de soja (\%) }\end{array}$} & \multirow[t]{2}{*}{ EP } & \multirow[t]{2}{*}{$\mathrm{CV}$} \\
\hline & 0 & 50 & 100 & & \\
\hline PVI (kg) & 66,97 & 72,97 & 70,28 & 4,08 & - \\
\hline PVF (kg) & 81,02 & 82,97 & 80,18 & 5,30 & 16,39 \\
\hline \multicolumn{6}{|l|}{ Ingestão } \\
\hline MS (\%PC) & 2,66 & 2,81 & 3,31 & 0,20 & 16,33 \\
\hline $\operatorname{MS}\left(\mathrm{g} / \mathrm{PC}^{0,75}\right)$ & 78,21 & 83,72 & 96,39 & 5,69 & 16,18 \\
\hline MS (kg/dia) & 1,99 & 2,21 & 2,42 & 0,19 & 20,59 \\
\hline MO (kg/dia) & 1,88 & 2,06 & 2,26 & 0,17 & 20,62 \\
\hline PB (kg/dia) & $0,26 \mathrm{~b}$ & $0,33 \mathrm{ab}$ & $0,39 \mathrm{a}$ & 0,03 & 20,32 \\
\hline FDN (kg/dia) & $0,62 b$ & $0,88 \mathrm{~b}$ & $1,20 \mathrm{a}$ & 0,07 & 20,04 \\
\hline FDN (\%PC) & $0,82 b$ & $1,12 b$ & $1,64 \mathrm{a}$ & 0,08 & 17,19 \\
\hline \multicolumn{6}{|l|}{ Digestibilidade } \\
\hline MS (\%) & 69,63 & 71,18 & 72,61 & 1,32 & 4,54 \\
\hline MO (\%) & 70,56 & 72,36 & 74,71 & 1,29 & 4,37 \\
\hline PB (\%) & 67,47 & 72,89 & 75,25 & 2,84 & 9,68 \\
\hline FDN $(\%)$ & $43,77 \mathrm{c}$ & $53,83 \mathrm{~b}$ & $63,81 \mathrm{a}$ & 1,85 & 8,43 \\
\hline
\end{tabular}

${ }^{1} 0 \%$ CGS-0\% de casca do grão de soja em substituição ao milho moído, $50 \%$ CGS-50\% de casca do grão de soja em substituição ao milho moído, $100 \%$ CGS-100\% de casca do grão de soja em substituição ao milho moído.

Médias seguidas por letras diferentes na mesma linha, diferem pelo teste Tukey a $5 \%$ de probabilidade.

Os valores de ingestão e digestibilidade da MS, PB e FDN obtidos com $50 \%$ CGS, que corresponde a $19,46 \%$ de CGS na MS, foram semelhantes aos observados por Mouro et al. (2002), que, em pesquisa com cabras Saanen (50 kg PC) em lactação, utilizaram ração com 15,0\% de CGS na MS e observaram IMS de 1,89 kg/dia, IPB de 0,34 kg/dia e IFDN de $0,63 \mathrm{~kg} /$ dia e coeficientes de digestibilidade da MS, PB e FDN de 69,00; 69,73 e 57,25\%, respectivamente.

Ensaios de digestibilidade comprovaram que a utilização de CGS para cabritos em crescimento (Hashimoto et al, 2007), cabras em lactação (Zambom et al., 2007) e vacas em lactação (Ipharraguerre et al., 2002b; Hindrichsen et al., 2006) não altera a digestibilidade da matéria seca e aumenta a digestibilidade da fibra, o que confirma a boa utilização da parede celular na fermentação ruminal, resultando em efeito associativo positivo que possibilita a substituição parcial ou total o milho das rações.

Os tratamentos não alteraram $(\mathrm{P}>0,05)$ o peso corporal inicial e final (Tabela 5). Entretanto, a inclusão total da CGS resultou em maiores ingestões $(\mathrm{P}<0,05)$ de $\mathrm{MS}, \mathrm{PB}, \mathrm{MO}$ e FDN durante o pré-parto.

Os valores obtidos para nitrogênio uréico no plasma foram de 10,38; $10,92 \mathrm{e} 14,91 \mathrm{mg} / \mathrm{dL}$ para os tratamentos 0 , 50 e $100 \%$ CGS, respectivamente. A maior concentração de nitrogênio uréico no plasma observada para o tratamento $100 \%$ CGS provavelmente foi reflexo da maior ingestão de PB.

A ingestão de matéria seca por cabras em final de gestação é menor (Zambom et al., 2006), como conseqüência da compressão do rúmen pelo útero. A IMS média obtida neste estudo, de $1,38 \mathrm{~kg} / \mathrm{dia}$, corrobora os dados descritos por Schmidely et al. (1996), que, ao trabalharem com cabra em final de gestação, utilizaram a CGS como fonte de fibra rapidamente degradável em substituição ao amido e observaram IMS de 1,18 kg/dia. De forma semelhante, Goetsch et al. (2001) e Zambom et al. (2006), utilizando cabras em final de gestação, observaram IMS de 2,03 e de 1,14 kg/dia $(1,62 \% \mathrm{PC})$, respectivamente.

Os níveis de CGS não influenciaram as digestibilidades da MS e MO $(\mathrm{P}>0,05)$. No entanto, as melhores digestibilidades da PB e da FDN foram observadas quando adicionada a casca do grão de soja na ração. A concentração de FDN na dieta está negativamente correlacionada à IMS, em razão da fermentação mais lenta e do maior tempo de permanência no rúmen. Entretanto, o fornecimento de fibra mais digestível pode estimular o consumo, em virtude do aumento da taxa de passagem (Robinson \& McQueen, 1997), o que foi observado com o uso da casca do grão de soja nas rações.

Tabela 5 - Peso corporal inicial (PCI) e final (PCF) e ingestão e digestibilidade de nutrientes em cabras Saanen no pré-parto alimentadas com rações com casca do grão de soja em substituição ao milho moído

\begin{tabular}{|c|c|c|c|c|c|}
\hline \multirow[t]{2}{*}{ Item } & \multicolumn{3}{|c|}{$\begin{array}{l}\text { Nível de casca do } \\
\text { grão de soja }(\%)\end{array}$} & \multirow[t]{2}{*}{ EP } & \multirow[t]{2}{*}{$\mathrm{CV}$} \\
\hline & 0 & 50 & 100 & & \\
\hline PCI (kg) & 87,20 & 89,22 & 76,38 & 4,45 & 12,94 \\
\hline $\mathrm{PCF}(\mathrm{kg})$ & 87,00 & 93,63 & 77,80 & 4,54 & 12,91 \\
\hline \multicolumn{6}{|l|}{ Ingestão } \\
\hline MS (\%PC) & $1,18 \mathrm{c}$ & $1,56 \mathrm{~b}$ & $2,17 \mathrm{a}$ & 0,09 & 14,22 \\
\hline $\operatorname{MS}\left(\mathrm{g} / \mathrm{PC}^{0,75}\right)$ & $36,21 \mathrm{c}$ & $48,14 \mathrm{~b}$ & $64,08 \mathrm{a}$ & 2,75 & 13,63 \\
\hline MS (kg/dia) & $1,05 \mathrm{~b}$ & $1,43 \mathrm{a}$ & $1,67 \mathrm{a}$ & 0,10 & 16,88 \\
\hline MO (kg/dia) & $0,98 b$ & $1,33 \mathrm{a}$ & $1,54 \mathrm{a}$ & 0,09 & 16,95 \\
\hline PB (kg/dia) & $0,13 b$ & $0,22 \mathrm{a}$ & $0,28 \mathrm{a}$ & 0,01 & 17,34 \\
\hline FDN (kg/dia) & $0,32 \mathrm{c}$ & $0,55 \mathrm{~b}$ & $0,79 \mathrm{a}$ & 0,04 & 16,11 \\
\hline FDN (\%PC) & $0,36 \mathrm{c}$ & $0,59 b$ & $1,03 \mathrm{a}$ & 0,04 & 13,95 \\
\hline \multicolumn{6}{|l|}{ Digestibilidade } \\
\hline MS (\%) & 56,59 & 56,40 & 56,71 & 2,79 & 12,06 \\
\hline MO (\%) & 60,78 & 60,55 & 60,61 & 2,55 & 10,29 \\
\hline PB (\%) & $42,36 b$ & $58,43 \mathrm{a}$ & $64,58 \mathrm{a}$ & 2,88 & 12,81 \\
\hline FDN (\%) & $33,49 b$ & $37,54 \mathrm{ab}$ & $44,20 \mathrm{a}$ & 2,48 & 15,80 \\
\hline
\end{tabular}

${ }^{1} 0 \%$ CGS-0\% de casca do grão de soja em substituição ao milho moído, 50\%CGS-50\% de casca do grão de soja em substituição ao milho moído, $100 \%$ CGS $-100 \%$ de casca do grão de soja em substituição ao milho moído.

Médias seguidas por letras diferentes na mesma linha diferem pelo teste Tukey a $5 \%$ de probabilidade. 
Os níveis de CGS não afetaram a digestibilidade da MS $(\mathrm{P}>0,05)$ durante a lactação e no período pré-parto, mas diminuíram $25,78 \%$ da digestibilidade da matéria seca na fase pré-parto em relação à fase de lactação anterior, o que provavelmente está relacionado às diferenças no metabolismo animal nas fases fisiológicas.

Em ambas as fases fisiológicas, a inclusão de CGS melhorou a digestibilidade da fibra e possibilitou maiores resultados no período de lactação, o que possivelmente proporcionou maior taxa de passagem e maior ingestão de matéria seca.

A casca do grão de soja mostrou-se um alimento alternativo para melhorar a ingestão de matéria seca durante o período pré-parto, pois o tratamento $100 \%$ CGS proporcionou maior ingestão de nutrientes, sem alterar a DMS, e aumentando a digestão da proteína bruta e da fibra.

Os parâmetros de produção de leite ( $\mathrm{kg}$ por dia, $\mathrm{kg} / \mathrm{dia}$ corrigido para 3,5\% de gordura), eficiência de produção de leite e composição do leite (porcentagens de gordura, proteína, lactose, sólidos totais, acidez, densidade e CCS) não diferiram $(\mathrm{P}>0,05)$ entre as dietas experimentais, porém, para a concentração de nitrogênio uréico no leite foi maior com o nível de $50 \%$ CGS (Tabela 6).

A composição do leite de cabra pode variar de acordo com diversos fatores, como tipo e composição da dieta dos animais, raça, período de lactação e clima, além da ação combinada destes fatores nas condições ambientais de cada país ou região (Queiroga \& Costa, 2004). Assim, é importante conhecer os valores médios de composição do leite de cabra. Prata et al. (1998) avaliaram 179 amostras de leite de cabras Saanen e obtiveram os seguintes resultados: $3,74 \%$ de gordura, $3,27 \%$ de proteína, $4,35 \%$ de lactose, $11,51 \%$ de sólidos totais, $1,0324 \mathrm{~g} / \mathrm{cm}^{3}$ de densidade e $16,11^{\circ} \mathrm{D}$ de acidez.

Os valores obtidos para os teores de gordura $(3,35 \%)$, proteína $(2,86 \%)$, densidade $\left(1,026 \mathrm{~g} / \mathrm{cm}^{3}\right)$ e acidez $\left(14,60^{\circ} \mathrm{D}\right)$ foram menores que os observados por Prata et al. (1998), provavelmente em virtude das diferenças genéticas, do estado sanitário dos animais, do tipo de alimentação utilizada, do ambiente ou da associação desses fatores.

A utilização de alimentos com elevado teor de fibra em detergente neutro e com tamanho de partículas grandes tende a elevar o teor de gordura no leite, sem modificar a produção de leite. No entanto, alimentos com elevado teor de fibra, mas com partículas pequenas, normalmente reduzem a efetividade da fibra e, assim, não elevam o teor de gordura do leite. Esse efeito foi observado neste estudo e corrobora os descritos por Mouro et al. (2002), que utilizaram
Tabela 6 - Produção de leite (PL, kg/dia), produção de leite corrigida para $3,5 \%$ de gordura (PLG), produção de leite total (PLT, $\mathrm{kg}$ ), eficiência de produção de leite ( $\mathrm{kg}$ de leite produzido/kg de MS ingerida - EPL) e composição do leite de cabras Saanen em lactação alimentadas com rações com casca do grão de soja em substituição ao milho moído

\begin{tabular}{|c|c|c|c|c|c|}
\hline \multirow[t]{2}{*}{ Item } & \multicolumn{3}{|c|}{$\begin{array}{l}\text { Nível de casca do } \\
\text { grão de soja (\%) }\end{array}$} & \multirow[t]{2}{*}{ EP } & \multirow[t]{2}{*}{ CV } \\
\hline & 0 & 50 & 100 & & \\
\hline PL (kg/dia) & 2,47 & 2,33 & 3,38 & 0,33 & 29,67 \\
\hline PLG (kg/dia) & 2,35 & 2,29 & 3,42 & 0,33 & 30,45 \\
\hline PLT (kg) & 468,91 & 430,72 & 662,1 & 72,10 & 33,93 \\
\hline EPL & 1,22 & 1,06 & 1,39 & 0,12 & 23,70 \\
\hline Gordura (\%) & 3,18 & 3,19 & 3,69 & 0,19 & 13,91 \\
\hline Proteína $(\%)$ & 2,91 & 2,84 & 2,83 & 0,05 & 4,30 \\
\hline Lactose $(\%)$ & 4,23 & 4,18 & 4,25 & 0,06 & 3,27 \\
\hline $\begin{array}{l}\text { Sólidos } \\
\text { totais }(\%)\end{array}$ & 11,22 & 11,10 & 11,69 & 0,25 & 5,41 \\
\hline $\begin{array}{l}{ }^{1} \mathrm{NUL} \\
(\mathrm{mg} / \mathrm{dL})\end{array}$ & $18,19 b$ & $24,05 \mathrm{a}$ & $20,33 \mathrm{ab}$ & 1,51 & 17,77 \\
\hline Acidez ${ }^{\circ} \mathrm{D}$ & 15,65 & 14,21 & 13,95 & 1,06 & 17,85 \\
\hline Densidade & 1,027 & 1,027 & 1,026 & 0,00 & 0,08 \\
\hline $\begin{array}{l}{ }^{2} \mathrm{CCS} \\
(\mathrm{cel} / \mathrm{mL} \times 1000)\end{array}$ & $1.218,48$ & $1.160,31$ & 594,28 & 263,16 & 65,04 \\
\hline
\end{tabular}

${ }^{1} \mathrm{NUL}$ : nitrogênio uréico no leite; ${ }^{2} \mathrm{CCS}$ : contagem de células somáticas. Médias seguidas por letras diferentes na mesma linha diferem pelo teste Tukey a $5 \%$ de probabilidade.

CGS $(15,0 \%$ da MS) em rações para cabras Saanen (50 kg PC) em lactação e obtiveram produção de leite de $2,10 \mathrm{~kg} /$ dia com 2,95\% de proteína e 11,22\% de sólidos totais.

No entanto, Zenou \& Miron (2005) utilizaram a CGS em substituição a grãos com alto teor de amido na alimentação de ovelhas em lactação e observando maior IMS, IFDN, produção de leite e teor de gordura no leite no tratamento com CGS, porém, não notaram diferenças entre os tratamentos $(\mathrm{P}>0,05)$ para porcentagem de lactose e de sólidos totais no leite. As diferenças observadas no efeito da casca do grão de soja sobre o teor de gordura do leite podem ser atribuídas à sua utilização em combinação com diferentes tipos de alimentos, ou mesmo do número de animais utilizados.

A utilização da casca do grão de soja para cabras Saanen em lactação não modificou a produção e porcentagem de gordura do leite. Resultados similares foram obtidos por Modesto et al. (2001), que, utilizando CGS em substituição ao milho moído para vacas em lactação, não observaram diferenças $(\mathrm{P}>0,05)$ na produção e na porcentagem de gordura do leite. A produção de leite de ovelhas (Zervas et al., 1998) e vacas em lactação (Coomer et al., 1993; Ipharraguerre et al., 2002b; Hindrichsen et al., 2006) não foi alterada quando incluída CGS na ração. Entretanto, foi verificado efeito linear positivo para gordura no leite (\%), em decorrência da inclusão de CGS na ração. 


\section{Conclusões}

A utilização de casca do grão de soja em substituição ao milho moído em rações para cabras em lactação não altera a ingestão e a digestibilidade da matéria seca nem a produção e a composição do leite, mas melhora a digestibilidade da fibra em detergente neutro. A casca do grão de soja pode ser utilizada também durante o período pré-parto, pois favorece o aumento na ingestão de matéria seca e dos nutrientes e propicia a digestibilidade da fibra.

\section{Literatura Citada}

AGRICULTURAL AND FOOD RESEARCH COUNCIL - AFRC. Energy and Protein requirements of ruminant. Wallingford: CAB International, 1993. 159p.

COCHRAN, R.C.; ADAMS, D.C.; WALLACE, J.D. et al. Predicting digestibility of different diets with internal markers: evaluation of four potential markers. Journal of Animal Science, v.63, n.5, p.1476-1483, 1986.

COOMER, J.C.; AMOS, H.E.; WILLIAMS, C.C. et al. Response of early lactation cows to fat supplementation in diets with different nonstructural carbohydrate concentrations. Journal of Dairy Science, v.76, n.12, p.3747-3754, 1993.

DePETERS, E.J.; CANT, J.P. Nutritional factors influencing the nitrogen composition of bovine milk: a review. Journal of Dairy Science, v.75, p.2043-2070, 1992.

DRACKLEY, J.K. Biology of dairy cows during the transition period: the final frontier. Journal of Dairy Science, v.82, p.22592273, 1999.

GOETSCH, A.L.; DETWEILER, G.; SAHLU, T. et al. Dairy goat performance with different dietary concentrate levels in late lactation. Small Ruminant Research, v.41, p.117-125, 2001.

GRAVERT, H. O. Dairy cattle production. Nww York: Elsevier Science, 1987. 234p.

HASHimoto, J.H.; ALCALDE,C.R.; ZAMBOM, M.A. et al. Desempenho e digestibilidade aparente em cabritos Boer $\mathrm{x}$ Saanen em confinamento recebendo rações com casca do grão de soja em substituição ao milho. Revista Brasileira de Zootecnia, v.36, n.1, p.174-182, 2007.

HINDRICHSEN, I.K; WETTSTEIN, H.R.; MACHMÜLLER, A. et al. Digestive and metabolic utilization of dairy cows supplemented with concentrates characterized by different carbohydrates. Animal Feed Science and Technology, v.126, n.1-2, p.43-61, 2006.

IPHARRAGUERRE, I.R.; IPHARRAGUERRE, R.R.; CLARK, J.H. Performance of lactating dairy cows fed varying amounts of soyhulls as a replacement for corn grain. Journal of Dairy Science, v.85, n.11, p.2905-2912, 2002a.

IPHARRAGUERRE, I.R.; SHABI, Z.; CLARK, J.H. et al. Ruminal fermentation and nutrient digestion by dairy cows fed varying amounts of soyhulls as a replacement for corn grain. Journal of Dairy Science, v.85, n.11, p.2890-2904, 2002b.

IPHARRAGUERRE, I.R.; CLARK, J.H. et al. Soyhulls as an alternative feed for lactating dairy cows: a review. Journal of Dairy Science, v.86, n.4, p.1052-1073, 2003.

MARSH, W.H.; FINGERHUT, B.; MILLER, H. Automated and manual direct methods for the determination of blood urea. Journal of Clinical Chemistry, v.11, n.6, p.624-631, 1965.

MODESTO, E.C.; SANTOS, G.T.; ZAMBOM, M.A. et al. Casca do grão de soja na produção de leite. In: REUNIÃO ANUAL DA SOCIEDADE BRASILEIRA DE ZOOTECNIA, 38., 2001, Piracicaba. Anais... Piracicaba: Sociedade Brasileira de Zootecnia, 2001. p.1484-1485.
MOURO, G.F.; BRANCO, A.F.; MACEDO, F.A.F. et al. Substituição do milho pela farinha de mandioca de varredura em dietas de cabras em lactação: produção e composição do leite e digestibilidade dos nutrientes. Revista Brasileira de Zootecnia, v.31, n.1, p.475-483, 2002.

NATIONAL RESEARCH COUNCIL - NRC. Nutrient requirements of goats. Washington, D.C.: National Academy Science, 1981. 91p.

NATIONAL RESEARCH COUNCIL - NRC. Nutrient requirements of beef cattle. Washington, D.C.: National Academy Science, 1996. 242p.

NATIONAL RESEARCH COUNCIL - NRC. Nutrient requirements of dairy cattle. 7.rev.ed. Washington, D.C.: National Academy of Sciences, 2001. 381p.

PEREIRA, J.R.A.; ROSSI, P. Manual prático de avaliação nutricional de alimentos. 1.ed. Piracicaba: Fundação de Estudos Agrários Luiz de Queiroz, 1995. 34p.

PRATA, L.F.; RIBEIRO A.C.; REZENDE, K.T. et al. Composição, perfil nitrogenado e características do leite caprino (Saanen). Ciência e Tecnologia de Alimentos, v.18, n.4, p.428-432, 1998.

QUEIROGA, R.C.R.E.; COSTA, R.G. Composição do leite caprino. In: SIMPÓSIO INTERNACIONAL DE CONSERVAÇÃO DE RECURSOS GENÉTICOS: raças nativas para o semi-árido, 1. 2004, Recife. Anais... Recife: Universidade Federal Rural de Pernambuco, 2004. p.161-171.

ROBINSON, P.H.; McQUEEN, R.E. Influence of level of concentrate allocation and fermentability of forage fiber on chewing behavior and production of dairy cows. Journal of Dairy Science, v.80, n.4, p.681-691, 1997.

RODRIGUES, M.T. Alimentação de cabras leiteiras. In: ENCONTRO NACIONAL PARA O DESENVOLVIMENTO DA ESPÉCIE CAPRINA, 8., 2004, Botucatu. Anais...Botucatu: Faculdade de Medicina Veterinária e Zootecnia - UNESP, 2004. p.121-154.

SCHMIDELY, P.; ARCHIMÈDE, H.; BAS, P. et al. Effects of the synchronization of the rate of carbohydrates and nitrogen release of concentrate on rumen fermentation, plasma metabolites and insulin, in the dry pregnant goat. Animal Feed Science and Technology, v.63, p.163-178, 1996.

SCHMIDELY, P.; LLORET-PUJOL, M.; BAS, P. et al. Influence of feed intake and source of dietary carbohydrate on milk yield and composition, nitrogen balance, and plasma constituents of lactating goats. Journal of Dairy Science, v.82, p.747-755, 1999.

SILVA, D.C.; KAZAMA, R.; FAUSTINO, J.O. et al. Digestibilidade in vitro e degradabilidade in situ da casca do grão de soja, resíduo de soja e casca de algodão. Acta Scientiarum, v.26, n.4, p.501-506, 2004.

SILVA, D.J.; QUEIROZ, A.C. Análise de alimentos: métodos químicos e biológicos. 3.ed. Viçosa, MG: Universidade Federal de Viçosa, 2004. 235p.

SNIFFEN, C.J.; O'CONNOR, J.D.; Van SOEST, P.J. et al. A net carbohydrate and protein system for evaluating cattle diets: II. Carbohydrate and protein availability. Journal of Animal Science, v.70, n.10, p.3562-3577, 1992.

TRONCO, V.M. Manual de inspeção para a composição do leite. Santa Maria: Universidade Federal de Santa Maria, 1997. p. $88-110$.

UNIVERSIDADE FEDERAL DE VIÇOSA - UFV. SAEG - Sistema para análises estatísticas e genéticas. Versão 7.1. Viçosa, MG: 1997. 150p (Manual do usuário).

Van SOEST, P.J.; ROBERTSON, J.B.; LEWIS, B.A. Symposium: carbohydrate methodology, metabolism, and nutritional implications in dairy cattle. Journal of Dairy Science, v.74, n. 10, p.3583-3597, 1991.

ZAMBOM, M.A.; ALCALDE, C.R.; HASHimoto, J.H. et al. Parâmetros digestivos, produção e qualidade do leite de cabras Saanen recebendo rações com casca do grão de soja em substituição ao milho. Acta Scientiarum, v.29, n.3, p.309-316, 2007.

ZAMBOM, M.A.; ALCALDE, C.R.; MACEDO, F.A.F. et al. Ingestão, digestibilidade das rações e parâmetros sangüíneos em 
cabras Saanen durante o pré-parto recebendo rações com diferentes níveis de energia. Revista Brasileira de Zootecnia, v.35, n.4, p.1864-1869, 2006.

ZAMBOM, M.A.; ALCALDE, C.R.; SILVA, K.T. et al. Ingestão, digestibilidade das rações e produção de leite em cabras Saanen submetidas a diferentes relações de volumoso:concentrado. Revista Brasileira de Zootecnia, v.34, n.6, p.2505-2514, 2005 (supl.). ZAMBOM, M.A.; SANTOS, G.T.; MODESTO, E.C. et al. Valor nutricional da casca do grão de soja, farelo de soja, milho moído e farelo de trigo para bovinos. Acta Scientiarum, v.23, n.4, p.937-943, 2001 .

ZENOU, A.; MIRON, J. Milking performance of dairy ewes fed pellets containing soy hulls as starchy grain substitute. Small Ruminant Research, v.57, p.187-192, 2005.

ZERVAS, G.; FEGEROS, K.; KOYTSOTOLIS, K. et al. Soy hulls as a replacement for maize in lactationg dairy ewe diets with ou without dietary fat supplements. Animal Feed Science and Technology, v.76, p.65-75, 1998. 